\title{
Icariin promotes the proliferation and differentiation of osteoblasts from the rat mandible by the Wnt/ $\beta$-catenin signalling pathway
}

\author{
YUE WANG $^{1 *}$, RAN WANG $^{1,2^{*}}$ and FENGQIU ZHANG ${ }^{1}$ \\ ${ }^{1}$ Department of Periodontology, Beijing Stomatological Hospital, Capital Medical University, Beijing 100050; \\ ${ }^{2}$ Department of Stomatology, Beijing Shi Ji Tan Hospital, Capital Medical University, Beijing 100038, P.R. China
}

Received December 18, 2017; Accepted June 28, 2018

DOI: $10.3892 / \mathrm{mmr} .2018 .9334$

\begin{abstract}
Icariin (ICA) has been suggested to restore osteogenic function. Many bone defect diseases involve the mandible, which performs distinct functions and responds differently to stimuli from other bones. However, there are few reports describing the effect and mechanism of ICA on mandibular cells. Therefore, the aim of the present study was to determine the effect of ICA on the proliferation and differentiation of osteoblastic cells isolated from the rat mandible and to determine whether the Wnt/ $\beta$-catenin signalling pathway participates in this effect. The present study established an osteoblastic cell line from the rat mandible. ICA at concentrations between 0.15 and $15 \mu \mathrm{M}$ promoted the proliferation and differentiation of osteoblastic cells following a $72 \mathrm{~h}$ incubation. Furthermore, ICA elevated the mRNA expression levels of $\beta$-catenin, runt-related transcription factor 2, cyclin D1 and alkaline phosphatase in osteoblastic cells, and these effects were inhibited by the $\mathrm{Wnt} / \beta$-catenin pathway inhibitor Dickkopf- 1 ; thus, the Wnt/ $\beta$-catenin signalling pathway may be involved with the ICA-induced proliferation and differentiation of osteoblasts from the rat mandible. In conclusion, these results support the osteogenic effects of ICA $(0.15$ to $15 \mu \mathrm{M})$ on osteoblastic cells from the rat mandible and the participation of the $\mathrm{Wnt} / \beta$-catenin signalling pathway.
\end{abstract}

\section{Introduction}

The mandible is an especially dynamic bone. Despite its fundamental similarity to other bones, the mandible performs

Correspondence to: Professor Fengqiu Zhang, Department of Periodontology, Beijing Stomatological Hospital, Capital Medical University, 4 Tiantan Xili, Dongcheng, Beijing 100050, P.R. China E-mail: fengqiuzhang@126.com

${ }^{*}$ Contributed equally

Key words: icariin, Wnt/ $\beta$-catenin, osteoblast, mandible distinct functions and responds differently to mechanical, developmental, and homeostatic stimuli (1). Diverse differential and osteogenic potentials have been confirmed between mandible- and long bone-derived cells (2-4). Many bone defect diseases, such as osteomyelitis, bone cyst, periodontitis and trauma, involve this bone. Therefore, it is very important to evaluate the responses to external stimuli and the remodelling and healing potential of the mandible.

Icariin (ICA), the major effective ingredient of the plant herb Epimedium, is used to improve kidney yang in traditional Chinese medicine. Many reports have indicated that ICA can attenuate inflammation (5) and restore osteogenesis (6). ICA can stimulate the proliferation and osteoblastic differentiation of mesenchymal stem cells or long bone-derived cells through the Wnt/ $\beta$-catenin signalling pathway (6-9). However, there are few reports about the effect and mechanism of ICA on the differentiation and proliferation of osteoblastic cells from the mandible.

Therefore, this study mainly aimed to determine the effect of ICA on the proliferation and differentiation of osteoblastic cells isolated from the rat mandible and to determine whether the $\mathrm{Wnt} / \beta$-catenin pathway participates in this effect.

\section{Materials and methods}

Materials. ICA was purchased from the National Institute for the Control of Pharmaceutical and Biological Products (Beijing, China); Dickkopf-1 (DKK-1) was purchased from PeproTech, Inc. (Rocky Hill, NJ, USA); foetal bovine serum (FBS) was obtained from Gibco, USA; high glucose Dulbecco's modified Eagle medium (H-DMEM), penicillin, streptomycin and trypsin were purchased from Hangzhou Jinuo Biotechnology Co., Ltd. (Hangzhou, China); all the plates and flasks used for cell culture were purchased from Corning, USA; an alkaline phosphatase (ALP) staining kit, Cell Counting kit-8 (CCK-8) and ALP activity detection kit were purchased from Nanjing Jiancheng Bioengineering Institute (Nanjing, China).

Isolation of osteoblastic cells from a rat mandible. A new born $\mathrm{C} 57$ rat was sacrificed and immersed in $70 \%$ ethanol for $10 \mathrm{~min}$; then, the mandible body was isolated from the soft tissue, washed with phosphate-buffered saline (PBS; containing $200 \mathrm{IU} / \mathrm{ml}$ penicillin and $200 \mu \mathrm{g} / \mathrm{ml}$ streptomycin) 
three times and cut into small pieces with diameters between 1 and $2 \mathrm{~mm}$. Two millilitres of $0.25 \%$ trypsin with ethylenediaminetetraacetic acid was added to the tube containing the mandible pieces, which were incubated for $30 \mathrm{~min}$ in a $37^{\circ} \mathrm{C}$ water bath and then centrifuged at $1,100 \mathrm{r} / \mathrm{min}$. The pellet was collected, and PBS was added for 5 additional centrifugations. The pellet was finally resolved in H-DMEM containing 15\% FBS, $200 \mathrm{IU} / \mathrm{ml}$ penicillin and $200 \mu \mathrm{g} / \mathrm{ml}$ streptomycin and cultured in an incubator $\left(37^{\circ} \mathrm{C}, 5 \% \mathrm{CO}_{2}\right)$ for $20 \mathrm{~min}$. Rarefied osteoblastic cells were obtained after the fibroblasts with differential attachment were removed. These cells were maintained in H-DMEM with 15\% FBS, $200 \mathrm{IU} / \mathrm{ml}$ penicillin, and $200 \mu \mathrm{g} / \mathrm{ml}$ streptomycin, and $5 \mathrm{mM} \beta$-glycerophosphate, $100 \mathrm{mM}$ L-ascorbic acid, and $0.1 \mathrm{mM}$ dexamethasone were added for differentiation experiments. The growth situation of the osteoblastic cells was checked by cytometry. ALP staining and alizarin red staining were used to check the differentiation and mineralization of the isolated osteoblastic cells afterwards.

The present study was carried out in accordance with the recommendations of the National Institutes of Health Guide for the Care and Use of Experimental Animals. The protocol was approved by the Ethics Committee of Beijing Stomatological Hospital (Beijing, China).

Evaluation of the effects of ICA on osteoblastic cell proliferation and differentiation. Twenty micrograms of ICA (powder) was dissolved in $1 \mathrm{ml}$ of dimethyl sulfoxide (DMSO) and stored at $-20^{\circ} \mathrm{C}$. Later, a series of working concentrations $(0$, $0.0015,0.015,0.15,1.5,15,30,60$ and $100 \mu \mathrm{M})$ was obtained from this stock. Cells in the logarithmic growth phase were digested by trypsin.

For CCK-8 measurement, cells were seeded in 96-well plates at 4,000 cells per well. Forty-eight h later, different working concentrations of ICA were added to the well, and the control sample was treated with DMSO. All the cells were then divided into three groups according to the incubation period, namely, 24, 48 and $72 \mathrm{~h}$. After a certain incubation time, the medium was aspirated, and $100 \mu \mathrm{l}$ of DMEM with $10 \mu \mathrm{l}$ of CCK-8 solution was added. According to the manufacturer's instructions, after $2 \mathrm{~h}$, the optical density (OD) value of each sample was determined by a microplate reader at a wavelength of $450 \mathrm{~nm}$.

For the ALP activity measurement, cells were seeded into 12-well plates at 50,000 cells per well. After a certain incubation period with ICA, the cells were harvested into $1.5-\mathrm{ml}$ Eppendorf (EP) tubes and lysed by $1 \%$ Triton X-100 for $30 \mathrm{~min}$. The supernatant was then collected after centrifugation at $12,000 \mathrm{r} / \mathrm{min}$ for $5 \mathrm{~min}$, the concentration of the total protein was determined using the bicinchoninic acid (BCA) method, and the ALP activity was measured using the ALP activity detection kit according to the manufacturer's procedure.

Expression of the mRNA of markers related to the Wnt/ $\beta$-catenin signalling pathway. Ten micrograms of DKK-1 was dissolved in $5 \mathrm{ml}$ of PBS (containing 10\% FBS), and the working concentration of DKK-1 was $0.1 \mu \mathrm{g} / \mathrm{ml}$. Osteoblastic cells were seeded in $35-\mathrm{mm}$ dishes at $1 \times 10^{5} / \mathrm{ml}$ and cultured for 3 days. Then, the cells were treated with $1.5 \mu \mathrm{M}$ ICA, $0.1 \mu \mathrm{g} / \mathrm{ml}$ DKK-1 or their mixture, and DMSO-treated cells were used as a control. The cells were again divided into three groups
Table I. Primers used to amplify $\beta$-catenin, RUNX2, ALP and cyclin D1.

\begin{tabular}{|c|c|}
\hline Primer & Sequence $\left(5^{\prime}-3^{\prime}\right)$ \\
\hline$\beta$-catenin & $\begin{array}{l}\text { Forward: TGCTGAAGGTGCTGTCTGTC } \\
\text { Reverse: TCGCTGACTTGGGTCTGTC }\end{array}$ \\
\hline RUNX2 & $\begin{array}{l}\text { Forward: CCTCTGACTTCTGCCTCTGG } \\
\text { Reverse: ATGAAATGCTTGGGAACTGC }\end{array}$ \\
\hline ALP & $\begin{array}{l}\text { Forward:CTTGCTGGTGGAAGGAGGCAGG } \\
\text { Reverse: GGAGCACAGGAAGTTGGGAC }\end{array}$ \\
\hline Cyclin D1 & $\begin{array}{l}\text { Forward: CAGAAGTGCGAAGAGGAGGT } \\
\text { Reverse: GCAGTCAAGGGAATGGTCTC }\end{array}$ \\
\hline
\end{tabular}

RUNX2, runt-related transcription factor 2; ALP, alkaline phosphatase.

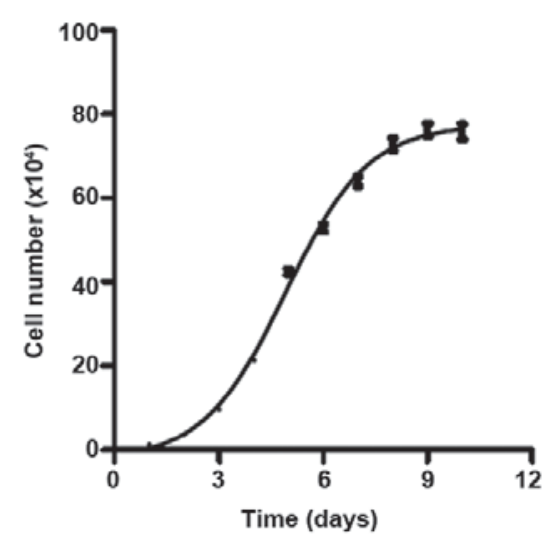

Figure 1. Growth curve of the osteoblastic cells isolated from the rat mandible. Cells grew at a lower rate at the beginning. Subsequently, the cells entered the exponential phase on day 2 and remained at the plateau phase from days 8-10.

with incubation times of 24,48 and $72 \mathrm{~h}$. After each incubation period, reverse transcription-quantitative polymerase chain reaction (RT-qPCR) was performed to determine the gene expression level of the marker proteins, including $\beta$-catenin, cyclin D1, runt-related transcription factor 2 (RUNX2) and ALP. Total RNA was isolated using TRIzol reagent (Sunbio, Beijing, China) according to the manufacturer's instructions. cDNA was synthesized using a cDNA synthesis kit (Invitrogen; Thermo Fisher Scientific, Inc., Waltham, MA, USA) following the manufacturer's protocol. The cDNA was then amplified by RT-qPCR with the SYBR Premix Ex Taq kit (Takara Biotechnology, Otsu, Japan) and the following thermocycling conditions: $95^{\circ} \mathrm{C}$ for $10 \mathrm{~min}$, followed by 45 cycles of $95^{\circ} \mathrm{C}$ for $10 \mathrm{sec}, 60^{\circ} \mathrm{C}$ for $30 \mathrm{sec}$ and $72^{\circ} \mathrm{C}$ for $30 \mathrm{sec}$. The primers used are shown in Table I. Each sample was assessed in triplicate and analysed using the $2^{-\Delta \Delta \mathrm{Cq}}$ method (10).

Data analysis and statistical methods. The data were analysed using GraphPad 5.0 software (GraphPad Software, Inc., La Jolla, CA, USA). Every type of experiment was repeated 4 times, and the results were presented as the mean \pm standard deviation. The results were first checked for normality and homogeneity using a Kolmogorov-Smirnov test. A t-test was used to compare two independent groups. For experiments 
A

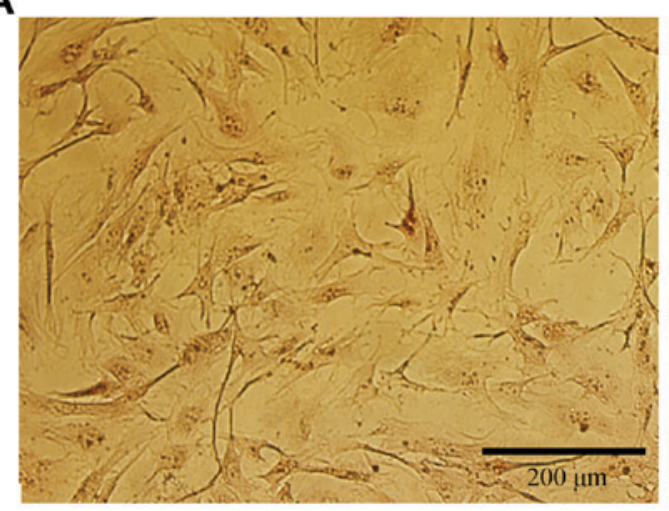

B

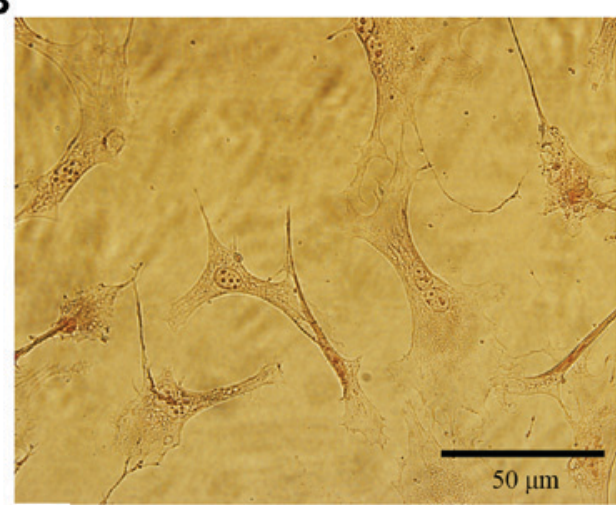

Figure 2. ALP staining of osteoblastic cells. (A) Following osteoblastic cell culture for $36 \mathrm{~h}$, cells were stained to check for ALP. The grey granular material indicates positive ALP staining. The positive staining rate was $96.2 \%$ (scale bar, $200 \mu \mathrm{m}$ ). (B) High magnitude image of ALP staining presented in part (A). Scale bar, $50 \mu \mathrm{m}$. ALP, alkaline phosphatase.

divided into several groups, statistical analysis was performed by one-way analysis of variance with Tukey's post hoc pairwise comparisons. $\mathrm{P}<0.05$ was considered to indicate a statistically significant difference.

\section{Results}

Isolation of osteoblastic cells from a rat mandible. The growth curve of osteoblastic cells isolated from a rat mandible was obtained (Fig. 1). The curve met the criteria for a classic cell growth curve, which contains four phases: lag phase, log phase, stationary phase and death phase. The cells were in the $\log$ phase between day 2 and day 6 ; therefore, this period was selected for cell treatments.

We performed ALP staining by using the ALP activity detection kit. Over $95 \%$ of the osteoblasts were stained by the ALP marker (Fig. 2), indicating that these cells were healthy enough to express ALP. The osteoblastic cells showed a typical morphology with a fibroblast appearance: Most showed an irregular fusiform shape. These cells also firmly adhered to the plate.

The mineralization of the isolated osteoblastic cells was checked by alizarin red staining. After 21 days of culture, many red dots were visible under a microscope (Fig. 3). Those dots were the mineralized calcium nodules, suggesting that the osteoblasts can grow well until mineralization and maturation.

ICA influences the proliferation and differentiation of osteoblastic cells. The proliferation level of osteoblastic cells in groups with different stimuli and treatment times was determined by the CCK-8 method (Fig. 4). The cells treated with DMSO were used as a blank control under this circumstance. ICA just can promote the proliferation of osteoblastic cells modestly after treatment for $24 \mathrm{~h}$ at concentrations between 0.0015 and $60 \mu \mathrm{M}$. In regard to $48 \mathrm{~h}$ of incubation, $0.0015 \mu \mathrm{M}$ ICA promoted the proliferation of osteoblastic cells significantly. With continued culture to $72 \mathrm{~h}$, ICA at concentrations between 0.15 and $15 \mu \mathrm{M}$ significantly promoted the proliferation of osteoblastic cells. However, $100 \mu \mathrm{M}$ ICA significantly suppressed the proliferation of osteoblastic cells at all time points.
The ALP activity was also determined to evaluate the effect of ICA on osteoblast differentiation (Fig. 5). ICA at certain concentrations significantly improved the ALP activity after the osteoblastic cells were treated for 24 or $48 \mathrm{~h}$, and ICA at concentrations between 0.015 and $15 \mu \mathrm{M}$ increased the ALP activity significantly after the cells were treated for $72 \mathrm{~h}$.

Participation of the Wnt/ $\beta$-catenin signalling pathway. To verify the role of the Wnt/ $\beta$-catenin signalling pathway in the effect of ICA, we determined the mRNA level of several marker proteins, including $\beta$-catenin, RUNX2, cyclin D1 and ALP (Fig. 6). The concentration of ICA applied was $1.5 \mu \mathrm{M}$ because of its significant proliferation and differentiation effect, as shown above (Fig. 4). DKK-1 is an inhibitor of the Wnt/ $\beta$-catenin signalling pathway and was used as a negative control. Compared with the mRNA levels of all the marker proteins in the control group, those in the ICA group were significantly increased at all time points of incubation; the one exception was the mRNA level of cyclin D1, which was slightly but not significantly increased at $24 \mathrm{~h}$. The mRNA levels of all the marker proteins in the control group were significantly suppressed by DKK-1 treatment, except the mRNA level of cyclin D1, which was slightly decreased at $24 \mathrm{~h}$. The elevating effects of ICA on the mRNA level of all the marker proteins were inhibited significantly in the ICA and DKK-1 mixture group at all time points, except the mRNA level of cyclin D1 at $24 \mathrm{~h}$.

\section{Discussion}

The osteoblastic cell line that we established from the rat mandible grew healthily and adherently. The cells expressed ALP at a considerable level, as almost all cells showed a positive ALP signal. Moreover, the osteoblastic cells had the classic standard shape and grew to mineralization. Overall, this osteoblastic cell line from the rat mandible was successfully established and was suitable for scientific study.

ICA influenced the proliferation and differentiation of the osteoblastic cells in a concentration- and time-dependent manner, and compared with 24 and 48-h treatments, the 72-h treatment had the largest effect. At this time point, the concentration dependence was bell shaped; only the middle concentrations, namely, $0.15,1.5$ and $15 \mu \mathrm{M}$, significantly 
A

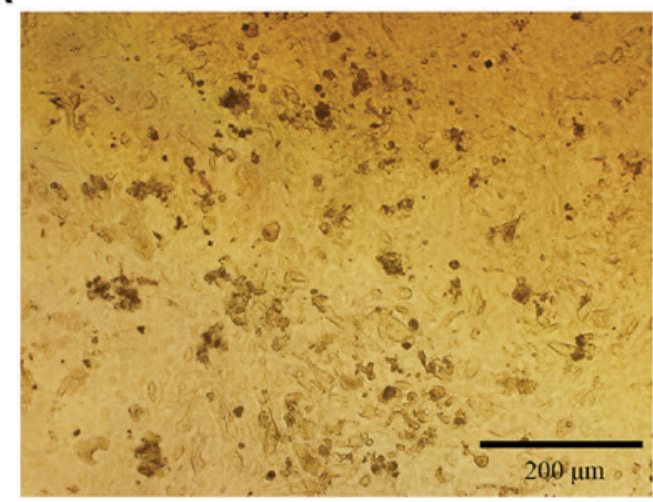

B

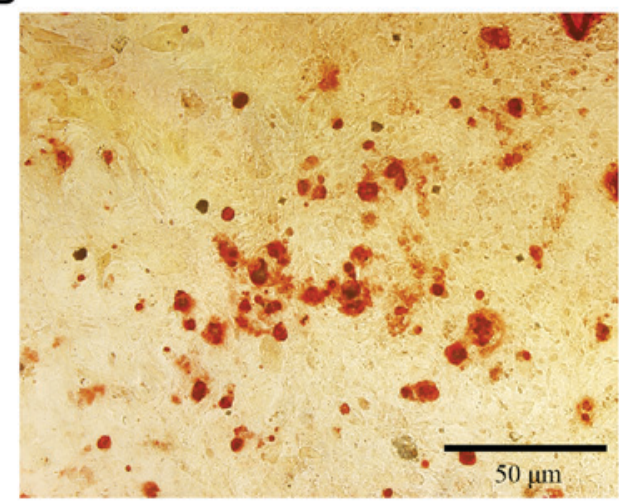

Figure 3. Alizarin red staining of osteoblastic cells. (A) Following osteoblastic cell culture for 21 days, the cells formed aggregates, and mineral nodules can be observed under an optical microscope (scale bar, $200 \mu \mathrm{m}$ ). (B) Mineralized nodules were dyed by alizarin red, becoming an orange precipitate (scale bar, $50 \mu \mathrm{m}$ ).

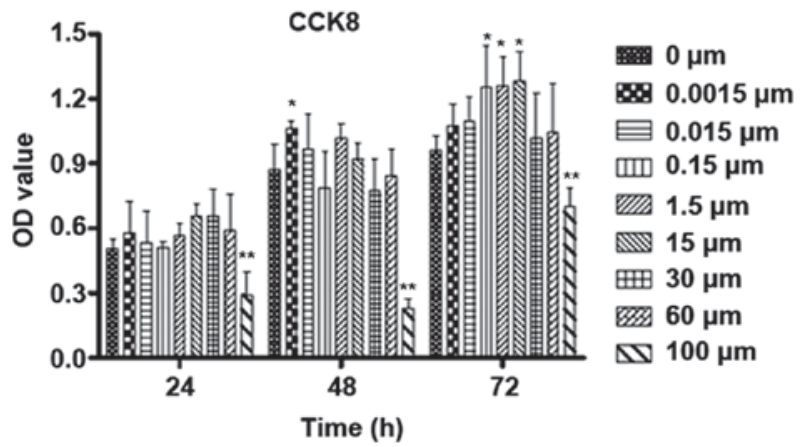

Figure 4. Influence of time and varied concentrations of ICA on the proliferation of osteoblastic cells. Osteoblastic cells were cultured for 24, 48 and $72 \mathrm{~h}$ with $0,0.0015,0.015,0.15,1.5,15,30,60$ and $100 \mu \mathrm{M}$ ICA. The proliferation was checked by CCK-8. ${ }^{*} \mathrm{P}<0.05$ and ${ }^{* *} \mathrm{P}<0.01$ vs. $0 \mu \mathrm{M}$ ICA. CCK-8, Cell Counting kit-8; ICA, icariin; OD, optical density.

increased the proliferation and differentiation of the osteoblastic cells. The ideal working concentration of ICA for the proliferation of this osteoblastic cell line in vitro is between 0.15 and $15 \mu \mathrm{M}$. This finding was consistent with other reports, which reported that the largest effect on osteoblastic cells from rat calvaria and the hFOB 1.19 human osteoblastic cell line for concentrations between 1 and $10 \mu \mathrm{M}(6,11)$. Treating the osteoblastic cells with $100 \mu \mathrm{M}$ ICA inhibited the proliferation and differentiation of the cells. The mechanism behind this effect is still unknown. One possibility could be that a high concentration of ICA can block some signalling pathways by elevating the levels of the inhibitors of some nuclear receptors. It will be interesting to pursue this idea in the future. One study showed that ICA could suppress the inflammatory response mediated by NF- $\kappa \mathrm{B}, \operatorname{PPAR} \alpha$ and PPAR $\gamma$ in rats (12), which indicated that ICA can interact with multiple pathways via many signalling molecules.

The cell line we established came from the rat mandible, and ICA at certain concentrations significantly increased the proliferation and differentiation of these osteoblastic cells. Thus, ICA could be used to treat mandible defect diseases, including osteomyelitis, bone cyst, periodontitis and trauma. Another feature of these diseases is the inflammatory response; since ICA can inhibit the inflammatory response in rat brains (12), ICA could be an ideal treatment for these

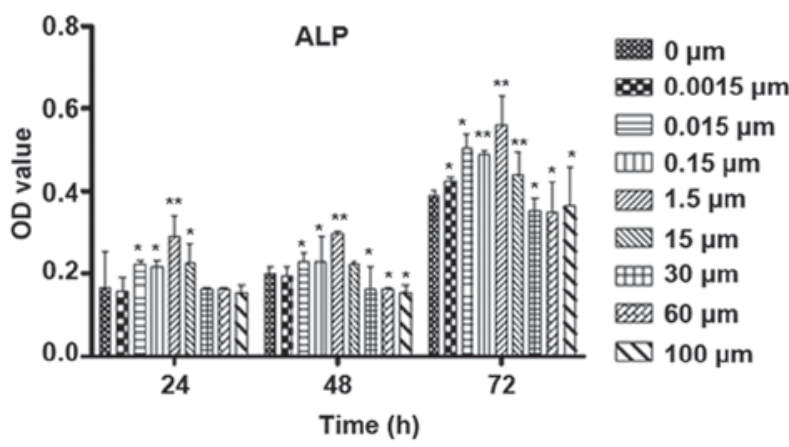

Figure 5. Influence of time and varied concentrations of ICA on the differentiation of osteoblastic cells. Osteoblastic cells were cultured for 24,48 and $72 \mathrm{~h}$ with $0,0.0015,0.015,0.15,1.5,15,30,60$ and $100 \mu \mathrm{M}$ ICA. The differentiation was evaluated by the levels of ALP activity. ${ }^{*} \mathrm{P}<0.05$ and ${ }^{* *} \mathrm{P}<0.01$ vs. $0 \mu \mathrm{M}$ ICA. ALP, alkaline phosphatase; ICA, icariin; OD, optical density.

diseases. However, this possibility requires more studies, especially in vivo studies, to develop this treatment.

We found that ICA increased the mRNA level of $\beta$-catenin, RUNX2, cyclin D1 and ALP. $\beta$-Catenin is the key protein of the Wnt/ $\beta$-catenin pathway, and RUNX2, cyclin D1 and ALP are target genes of the Wnt/ $\beta$-catenin pathway. Furthermore, this upregulation was inhibited by DKK-1, which inhibits the Wnt/ $\beta$-catenin pathway. Therefore, our study indicates that the $\mathrm{Wnt} / \beta$-catenin pathway participates in the effect of ICA on osteoblastic cells from the rat mandible. This finding is consistent with other reports, which indicated that the Wnt/ $\beta$-catenin pathway plays a role in the ICA-induced promotion of cells of other origins (7-9). Li et al (7) showed that the Wnt/ $\beta$-catenin pathway is important for improving osteoblast differentiation through ICA in bone marrow stromal cells obtained from the rat femur and bilateral tibia. Another article by Wang et al (9) determined that ICA induced osteogenic differentiation of mouse mesenchymal stem cells and promoted new bone formation in rat calvaria at a titanium-particle-induced osteolytic site via activation of the Wnt/ $\beta$-catenin signalling pathway. Recently, Liu et al (8) suggested that ICA promotes the proliferation and differentiation of mouse MC3T3-E1 cells exposed to overload by activating the $\mathrm{Wnt} / \beta$-catenin pathway. As a a shortcoming of our study, we did not examine the expression levels of proteins associated with the $\mathrm{Wnt} / \beta$-catenin pathway 
A

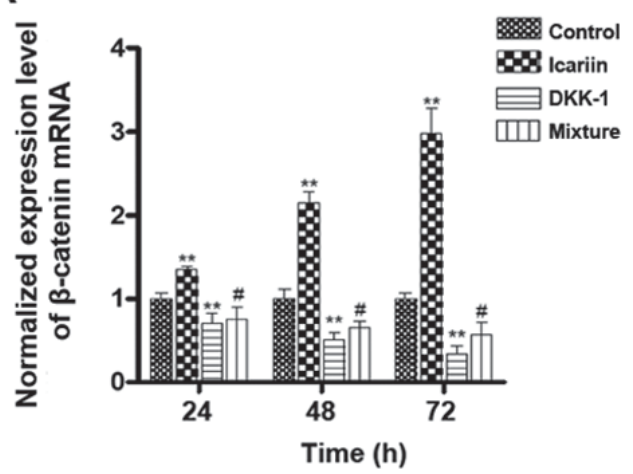

C

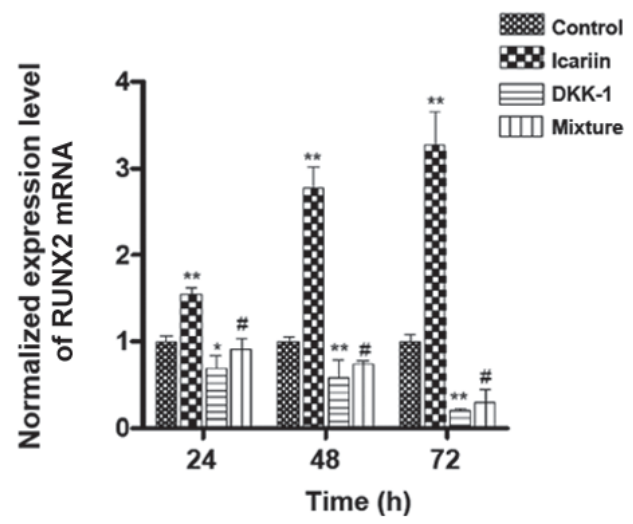

B
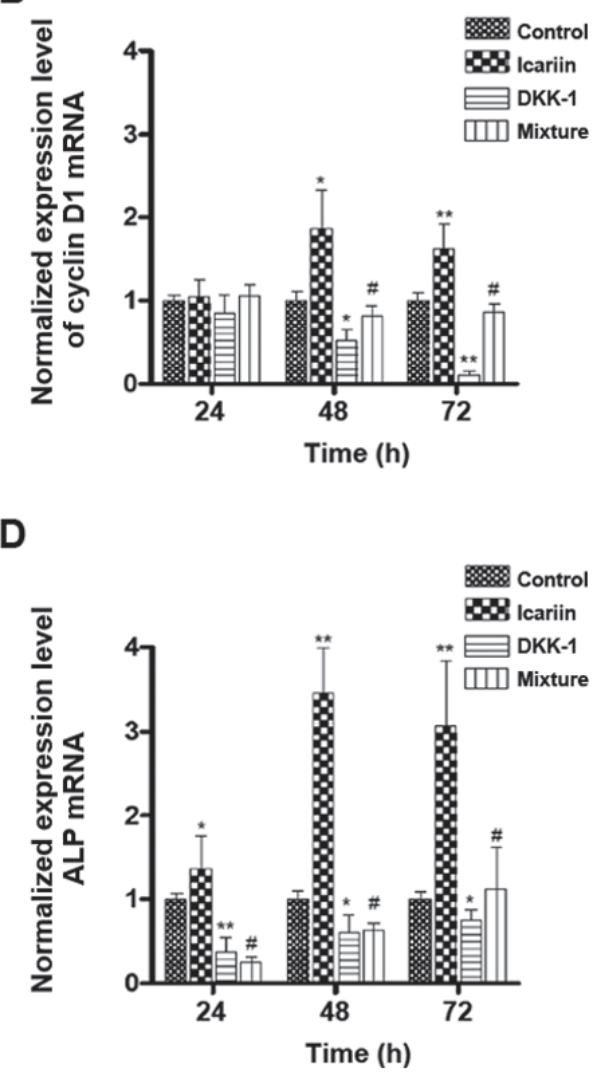

Figure 6. Participation of the Wnt $/ \beta$-catenin signalling pathway in the effects of ICA. Osteoblastic cells were treated with only medium (control), $1.5 \mu \mathrm{M}$ ICA, $0.1 \mu \mathrm{g} / \mathrm{ml}$ of the Wnt $/ \beta$-catenin pathway inhibitor DKK-1, or a mixture of ICA and DKK-1. All cells were incubated for 24 , 48 and 72 h. Reverse transcription-quantitative polymerase chain reaction was performed to determine the gene expression level of (A) $\beta$-catenin, (B) cyclin D1, (C) RUNX2 and (D) ALP. All of the expression levels were normalized to the control group. ${ }^{*} \mathrm{P}<0.05$ and ${ }^{* *} \mathrm{P}<0.01$ vs. control group; ${ }^{\text {"P }}<0.05$ vs. ICA group. DKK-1, Dickkopf-1; ICA, icariin; RUNX2, runt-related transcription factor 2; ALP, alkaline phosphatase.

and the effect that ICA has on these. Therefore, further related study is needed to supplement it.

Interestingly, the ICA mixed with DKK-1 group had higher mRNA levels of marker proteins after the 72-h incubation than the DKK-1 group, indicating that other signalling pathways may participate in the effects of ICA on osteoblastic cells. Some studies revealed that ICA affects the proliferation of osteoblasts through the BMP-2/Smad4 signal transduction pathway $(11,13)$, which is consistent with our results.

In summary, our study is the first to show that ICA promotes the proliferation and differentiation of osteoblastic cells isolated from the rat mandible and that the Wnt/ $\beta$-catenin pathway might be involved in this effect. More experiments are needed to confirm this mechanism and explore other signalling pathways. Our study also showed that our isolation of an osteoblastic cell line from the rat mandible was suitable for scientific research.

\section{Acknowledgements}

Not applicable.

\section{Funding}

The present study was supported by the Beijing Natural Science Foundation (grant no. 7122077) and the 4th
High Level Talents of the Beijing Health System (grant no. 201408).

\section{Availability of data and materials}

The datasets used during the current study are available from the corresponding author on reasonable request.

\section{Authors' contributions}

RW, YW and FZ participated in the research design, conducted the experiments, and performed the data analyses. YW and RW contributed to writing the manuscript. FZ contributed to revising the manuscript.

\section{Ethics approval and consent to participate}

The present study was conducted in accordance with the recommendations of the National Institutes of Health Guide for the Care and Use of Experimental Animals. The protocol was approved by the Ethics Committee of Beijing Stomatological Hospital.

\section{Patient consent for publication}

Not applicable. 


\section{Competing interests}

The authors declare that they have no competing interests.

\section{References}

1. Sodek J and McKee MD: Molecular and cellular biology of alveolar bone. Periodontol 2000 24: 99-126, 2000.

2. Aghaloo TL, Chaichanasakul T, Bezouglaia O, Kang B, Franco R, Dry SM, Atti E and Tetradis S: Osteogenic potential of mandibular vs. long-bone marrow stromal cells. J Dent Res 89: 1293-1298, 2010.

3. Akintoye SO, Lam T, Shi S, Brahim J, Collins MT and Robey PG: Skeletal site-specific characterization of orofacial and iliac crest human bone marrow stromal cells in same individuals. Bone 38: 758-768, 2006.

4. Matsubara T, Suardita K, Ishii M, Sugiyama M, Igarashi A, Oda R, Nishimura M, Saito M, Nakagawa K, Yamanaka K, et al: Alveolar bone marrow as a cell source for regenerative medicine: Differences between alveolar and iliac bone marrow stromal cells. J Bone Miner Res 20: 399-409, 2005.

5. Wang Y, Wang YS, Song SL, Liang H and Ji AG: Icariin inhibits atherosclerosis progress in Apoe null mice by downregulating CX3CR1 in macrophage. Biochem Biophys Res Commun 470 845-850, 2016.

6. Ma HP, Ming LG, Ge BF, Zhai YK, Song P, Xian CJ and Chen KM: Icariin is more potent than genistein in promoting osteoblast differentiation and mineralization in vitro. J Cell Biochem 112: 916-923, 2011.
7. Li XF, Xu H, Zhao YJ, Tang DZ, Xu GH, Holz J, Wang J, Cheng SD, Shi Q and Wang YJ: Icariin augments bone formation and reverses the phenotypes of osteoprotegerin-deficient mice through the activation of Wnt/ $\beta$-catenin-BMP signaling. Evid Based Complement Alternat Med 2013: 652317, 2013.

8. Liu Y, Huang L, Hao B, Li H, Zhu S, Wang Q, Li R, Xu Y and Zhang X: Use of an osteoblast overload damage model to probe the effect of icariin on the proliferation, differentiation and mineralization of MC3T3-E1 cells through the Wnt $/ \beta$-catenin signalling Pathway. Cell Physiol Biochem 41: 1605-1615, 2017

9. Wang J, Tao Y, Ping Z, Zhang W, Hu X, Wang Y, Wang L, Shi J, Wu X, Yang $\mathrm{H}$, et al: Icariin attenuates titanium-particle inhibition of bone formation by activating the Wnt/ $\beta$-catenin signaling pathway in vivo and in vitro. Sci Rep 6: 23827, 2016.

10. Livak KJ and Schmittgen TD: Analysis of relative gene expression data using real-time quantitative PCR and the 2(-Delta Delta C(T)) method. Methods 25: 402-408, 2001.

11. Liang W, Lin M, Li X, Li C, Gao B, Gan H, Yang Z, Lin X, Liao $\mathrm{L}$ and Yang M: Icariin promotes bone formation via the BMP-2/Smad4 signal transduction pathway in the hFOB 1.19 human osteoblastic cell line. Int J Mol Med 30: 889-895, 2012.

12. Xiong D, Deng Y, Huang B, Yin C, Liu B, Shi J and Gong Q: Icariin attenuates cerebral ischemia-reperfusion injury through inhibition of inflammatory response mediated by NF- $\kappa B, P P A R \alpha$ and PPAR $\gamma$ in rats. Int Immunopharmacol 30: 157-162, 2016.

13. Hsieh TP, Sheu SY, Sun JS, Chen MH and Liu MH: Icariin isolated from Epimedium pubescens regulates osteoblasts anabolism through BMP-2, SMAD4, and Cbfa1 expression. Phytomedicine 17: 414-423, 2010. 